\title{
Numerical Investigation on Wheel-Rail Dynamic Vibration Excited by Rail Spalling in High-Speed Railway
}

\author{
Kaiyun Wang, Wanming Zhai, Kaikai Lv, and Zaigang Chen \\ State Key Laboratory of Traction Power, Southwest Jiaotong University, Chengdu 610031, China \\ Correspondence should be addressed to Kaiyun Wang; kywang@swjtu.edu.cn
}

Received 1 March 2016; Accepted 5 May 2016

Academic Editor: Mario Terzo

Copyright ( 2016 Kaiyun Wang et al. This is an open access article distributed under the Creative Commons Attribution License, which permits unrestricted use, distribution, and reproduction in any medium, provided the original work is properly cited.

\begin{abstract}
Spalling in contact surface of rail is a typical form of rolling contact fatigue, which is a difficult problem to solve in railway. Once the spalling occurs in the rail, the wheel-rail dynamic interaction will become more severe. The wheel-rail dynamic interaction is investigated based on the theory of vehicle-track coupled dynamics in this paper, where the excitation modes of the rail spalling failure are taken into consideration for high-speed wheel-rail system. A modified excitation model of rail spalling failure is proposed. It can enable the investigations on two kinds of excitation modes in wheel-rail system due to the rail spalling, including the pulse and the harmonic excitation modes. The excitation mode can be determined by the ratio of the spalling length to its critical length. Thus, the characteristics of wheel-rail dynamic vibration excited by two kinds of excitation are simulated in detail. Consequently, the limited value of the spalling length is suggested for high-speed railway.
\end{abstract}

\section{Introduction}

Spalling in contact surface of rail often appears with the depth of a few millimeters, as shown in Figure 1. It is a typical form of rolling contact fatigue between the wheel and the rail, which is a difficult problem to solve in railway. Once the spalling occurs in the rail, the wheel-rail dynamic interaction will become more severe when a train passes through the spalling zone, thus causing the abnormal vibration. In return, the evolution of the spalling in rail surface will be accelerated under the severe wheel-rail dynamic interactions, and the service life of the rail will be shortened.

A lot of researches on the rolling contact fatigue between the wheel and the rail have been carried out. The leading position of this research field has been dominated by UNIFE [1] and Japan and America [2-4]. In the early 1980s, a 3D nonHertzian model for elastic rolling contact was established by means of the variational principles in elastic mechanics [5]. Subsequently, the contact stress on the wheel-rail at steady state curving was calculated on the basis of the nonHertzian model [6]. Formula of elastic-plastic rolling contact was deduced by use of an augmented Lagrangian treatment and the equilibrium equation of continuum mechanics, and the numerical simulation was successfully applied to solve the 2D, elastic-plastic, and steady rolling contact [7-9]. Effects of a single crack in the rail contact surface on the rolling contact were investigated by a finite element method and a theory of fracture mechanics $[10,11]$. Afterwards, on the basis of this method and theory, a bruising crack was outlined by the ellipse located in the contact surfaces of the rail, and effect of this crack on the rolling contact was analyzed [12]. The rail profile was optimized by the theory of dynamic interaction between the wheel and the rail, which could reduce the rail contact stress by $30-80 \%$ [13]. Effects of the wheel-rail friction temperature on the rolling contact fatigue were investigated based on the theoretical method [14, 15]. The element and mechanical property of the bainitic steel were studied [16], and the results showed that the bainitic steel taking the place of the pearlitic steel can not only reduce the crack in the rail contact surface but also increase the hardness of the contact surface. Besides these theoretical studies on the rolling contact fatigue, many experimental researches have been performed. For example, the shelling in high rail of a curved track was analyzed by experiment, and the phenomenon of this shelling was successfully exhibited by the prototype of a testing apparatus $[1,17,18]$. Also, effect 


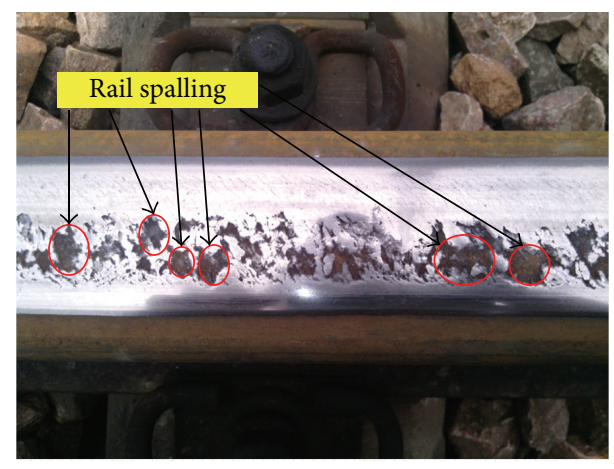

FIGURE 1: Spalling in rail surface.

of the attack angle on the flaking behavior of the pearlitic and bainitic steel was investigated by experiment [19], and results showed that the bigger the attack angle is, the more serious the fatigue will be. In addition, based on the attack angle, spallings may be initiated or formed from the viewpoint of balance between fatigue and wear.

Mechanism of the rolling contact fatigue has not been revealed completely up to now. However, some measurements are taken to reduce the damage caused by the shelling and spalling, such as developing the new material of the wheel and the rail, optimizing the profiles, and improving the performance of the track and the vehicle. Therefore, it is significant to carry out the investigation on the wheelrail dynamic vibration excited by the rail spalling, especially for high-speed railway. In this paper, a modified theoretical excitation model between the wheel and the rail due to rail spalling is proposed. Then, on the basis of the theory of vehicle-track coupled dynamics [20,21], characteristics of the wheel-rail dynamic interaction are investigated for a vehicle running on the track with spalling failure. Finally, the limited value of the spalling length is suggested for highspeed railway.

\section{Theoretical Excitation Models of the Rail Spalling}

In fact, there are multiple spallings existing on the rail surface, and there is difference in maintenance criterion between the multiple spallings and single spalling. But the wheel-rail interaction mechanism in the presence of the single spalling is the same as that with multiple spallings. So, a single spalling is taken into account in our preliminary studies which are explained in this paper in order to investigate the interaction mechanism.

2.1. Physical Model of the Rail Spalling. When a wheel passes through an area of the rail spalling, the contact situation between the wheel and the rail is illustrated in Figure 2, where the symbol $R$ denotes the radius of the wheel, $O$ represents the center point of the wheel, $V$ stands for the running speed of the vehicle, $L$ is the length of the rail spalling, $a$ denotes the spalling depth, and $h$ is the chord depth corresponding to

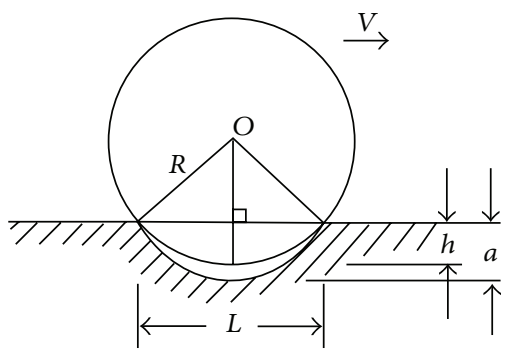

FIGURE 2: Schematic of contact situation between wheel and rail.

the chord length of the wheel set which is equal to the spalling length.

The mechanism of the contact between the wheel and the edge of spalling is complicated. Thus, many methods are used to analyze the contact mechanism. In this paper, the main assumption is that the spalling defect is regarded as an impact velocity or a rail irregularity, in which the detailed difference in the contact stiffness is neglected. That is to say, there is an additional impact velocity/irregularity when the wheel is passing through the area of the spalling defect, while it is Hertzian contact between the wheel and the rail still.

2.2. Traditional Excitation Model in Wheel-Rail System. According to the traditional model [20], there are two situations of the wheel set movement on the spalling region, as shown in Figure 3, where $\omega$ is the spinning angular velocity. When the wheel set runs with a low speed and reaches the marginal point $\mathrm{A}$ of the spalling region, the wheel set will rotate around point $A$ until it contacts another marginal point $B$. Then, it will rotate round point $B$, which results in the dynamic impact on the rail. When the wheel set runs with a high-speed and reaches point $\mathrm{A}$, the wheel set will lose contact with the rail and just go along a perfect parabola. Later, it will contact with point $\mathrm{B}$, which causes the dynamic impact on the rail.

Thus, it can be seen that there is a critical impact speed, which is used to determine the excitation model of the rail spalling in wheel-rail system.

In Figure 3(a) of the second situation, when the rotation angle of wheel set is $\phi / 2$, the critical point will appear. Therefore, the time $t_{1}$ is calculated by

$$
t_{1}=\frac{\phi / 2}{\omega}=\frac{R \phi}{2 V}
$$

The assumption is that $h$ is far lower than $R$. So, the time $t_{2}$ when the wheel set falls off the rail with a depth of $h$ is calculated by

$$
t_{2}=\sqrt{\frac{2 h}{\mu}},
$$

where $\mu$ is the impact acceleration of the wheel set.

When the wheel set loses contact with the rail, the loading condition is shown in Figure 4, where the symbols $M_{1}$ and $M_{2}$ are the sprung and unsprung mass of the primary 


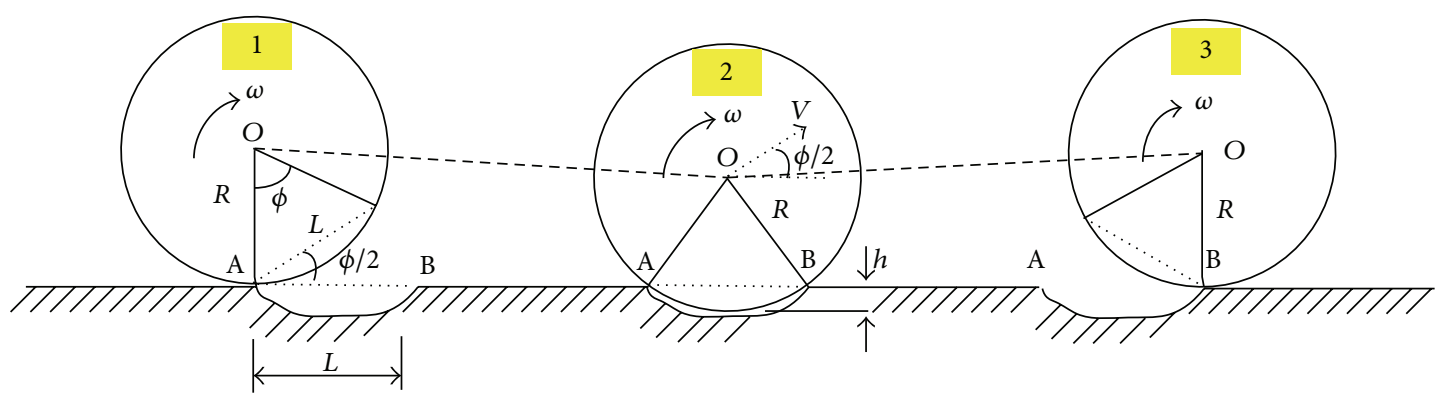

(a) Under the situation of a low running speed

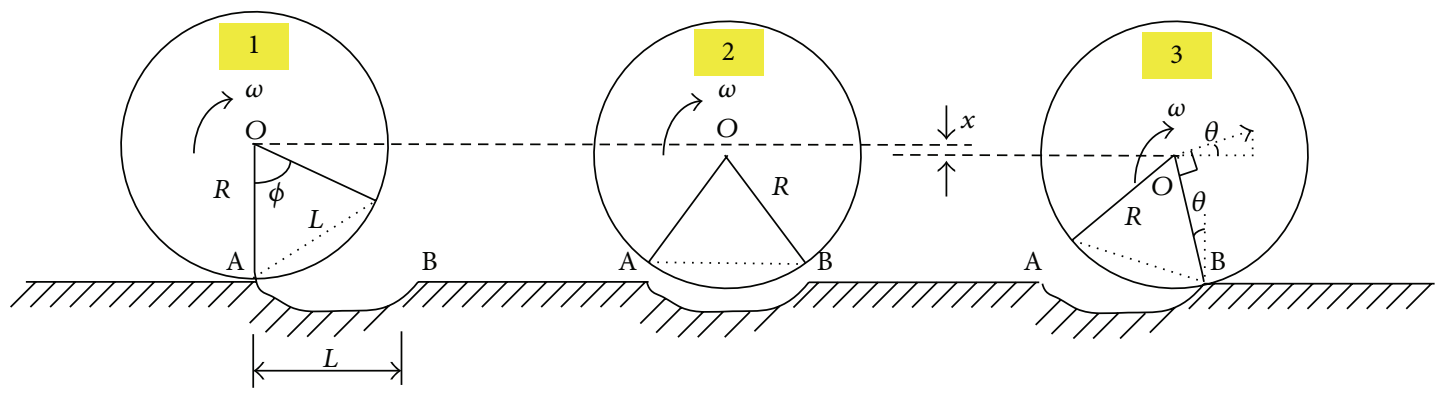

(b) Under the situation of a high running speed

FIGURE 3: Schematic of wheel set movement.

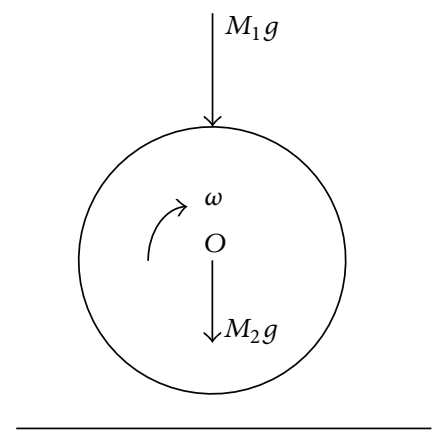

FIgURE 4: The loading condition of the wheel set.

suspension in the vehicle, respectively, and $g$ denotes the gravity acceleration $\left(g=9.8 \mathrm{~m} / \mathrm{s}^{2}\right)$.

Therefore, according to Newton's second law, $\mu$ is calculated by

$$
\mu=\frac{M_{1}+M_{2}}{M_{2}} g .
$$

If the time $t_{1}$ is just equal to the time $t_{2}$, the critical situation will occur. Thus, the speed of $V$ is defined as the critical impact speed, $V_{\text {cro }}$, which can be expressed as follows:

$$
V_{\text {cro }}=\sqrt{\mu R} .
$$

If the running speed is no more than the critical impact speed, the impact velocity between the wheel and the rail is expressed by

$$
v_{0}=(1+\gamma) \frac{L}{2 R} V,
$$

where $\gamma$ is the coefficient for converting the spinning inertia of the wheel into the reciprocating inertia, and it is usually valuated by 0.3 .

It can be known from (5) that the impact velocity is proportional to the spalling length and the running speed and is inversely proportional to the wheel radius.

Furthermore, if the running speed is higher than the critical impact speed, the impact velocity can be written by

$$
v_{0}=\frac{L}{V+\sqrt{\mu R}}\left[\mu+\gamma V \sqrt{\frac{\mu}{R}}\right] .
$$

2.3. Modified Excitation Model in Wheel-Rail System. If the spalling depth is bigger than the chord depth, the wheel cannot contact with the rail in the spalling region. For this case, the pulse excitation with a form of impact velocity between the wheel and the rail will be generated, which is calculated by (5) or (6).

If the spalling depth is smaller than the chord depth, the wheel always makes contact with the rail during the whole process when the wheel is passing through the spalling region. For this case, a harmonic model is proposed to represent this excitation of wheel-rail system in this paper, and it is regarded as a rail irregularity input from the wheelrail interface, which is expressed by

$$
Z_{0}(t)=\frac{1}{2} a(1-\cos \omega t) \quad\left(0 \leq t \leq \frac{L}{V}\right),
$$

where

$$
\omega=\frac{2 \pi V}{L} .
$$




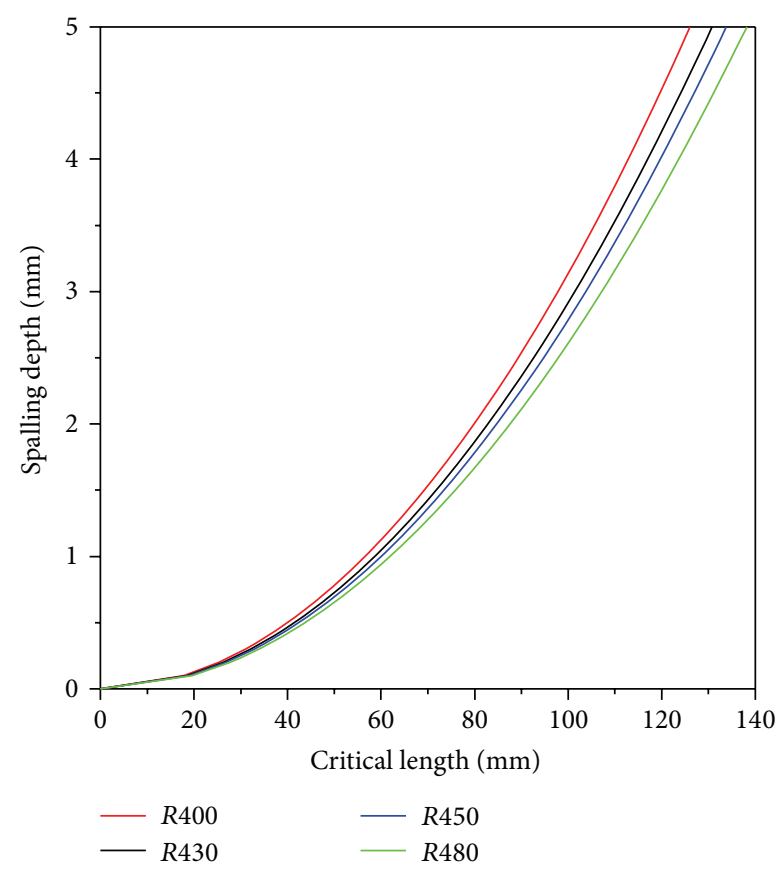

FIGURE 5: Critical length versus spalling depth.

It is worth noting that it is in the critical state between the pulse excitation and the harmonic excitation when the spalling depth is just equal to the chord depth. Thus, this spalling length is defined as the critical length, $L_{\mathrm{cr}}$, in this paper. According to the geometrical relationship shown in Figure 5, the critical length can be expressed by

$$
L_{\mathrm{cr}}=2 \sqrt{2 R a-a^{2}} \text {. }
$$

Suppose that a series of wheel radiuses are set as $400 \mathrm{~mm}, 430 \mathrm{~mm}, 450 \mathrm{~mm}$, and $480 \mathrm{~mm}$; then the relationship between the critical length and spalling depth can be obtained, as shown in Figure 5. It can be seen that, given a spalling depth, the larger the wheel radius is, the longer the critical length will be.

Therefore, the excitation modes in wheel-rail system can be judged by the ratio of the spalling length to its critical length. If the ratio is smaller than one, the wheel-rail system is under the pulse excitation with a form of impact velocity; otherwise, it is under the harmonic excitation.

\section{Vehicle-Track Coupled Dynamic Model}

The basic idea of the theory of vehicle-track coupled dynamics is that two independent subsystems, including a vehicle subsystem and a track subsystem, are taken as a unified system with a wheel-rail contact relationship as the link [20, 21]. It is usually used to investigate the dynamic behavior of the vehicle running on the elastic rail. Consequently, investigation on the wheel-rail dynamic interaction due to excitation of the rail spalling in high-speed railway is carried out on the basis of this theory.

As for the high-speed railway, there are two types of track structure, including the ballast track and the slab track.
In general, the irregularity of the slab track is better than that of the ballast track. Therefore, the ballast track is taken as an example in this paper. A vehicle-track coupled dynamic model [20] is adopted and shown in Figures 6 and 7, whose notations are defined in Nomenclature for the Parameters.

The vehicle submodel consists of seven principal rigid components, including one car body, two bogie frames, and four wheel sets. The car body is supported on two doubleaxle bogies which are linked with the wheel sets through the primary suspensions and connected with the car body through the secondary suspensions. The car body has the degrees of freedom (DOFs) of the vertical, lateral, yaw, roll, and pitch motions, as well as each bogie frame and wheel set. Consequently, the total number of the DOFs is 35 for the vehicle submodel.

The track submodel is a so-called five-parameter model [21], which is based upon the hypothesis that load transmission from a sleeper to the ballast approximately coincides with cone distribution. Both the left and the right rails are treated as continuous Bernoulli-Euler beams which are discretely supported at rail-sleeper junctions by three layers of springs and dampers, representing the elasticity and damping of the rail pad, ballast, and subgrade, respectively. The length of the beam is about 90 times that of the sleeper spacing, which can eliminate the boundary effect.

The wheel-rail coupled model is the essential element that couples the vehicle submodel with the track submodel at the wheel-rail interfaces. A spatial wheel-rail coupling model [20] is adopted to simulate the complex geometry in this paper. The nonlinear Hertzian elastic contact theory is used to calculate the wheel-rail normal contact forces according to the elastic compression deformations of wheels and rails at contact points in the normal directions. The tangential wheel-rail creep forces are calculated first by use of Kalker's linear creep theory and then modified by Shen-HedrickElkins nonlinear model. It is worth pointing out that the spalling defect is modeled as the external excitation in wheelrail system.

\section{Wheel-Rail Dynamic Interaction due to Pulse Excitation}

In order to investigate the wheel-rail dynamic interaction due to the pulse excitation in this section, the spalling length should be smaller than its critical length. For a new type of wheel with the radius of $430 \mathrm{~mm}$ in a high-speed vehicle, the critical length is $58.62 \mathrm{~mm}$ according to (9) by assuming the depth of the rail spalling to be $1 \mathrm{~mm}$. Moreover, the spalling length is kept as a constant, for example, $30 \mathrm{~mm}$ assumed here.

4.1. Characteristics of Wheel-Rail Vibration. When the vehicle passes through the spalling region at a speed of $350 \mathrm{~km} / \mathrm{h}$, the calculated wheel-rail vertical dynamic force is shown in Figure 8. It can be seen that an enormous wheel-rail dynamic force is produced, including a first peak of impact force (named $P_{1}$ force) and a second peak of impact force (named $P_{2}$ forces), and the maximum value is $136.05 \mathrm{kN}$. It is 


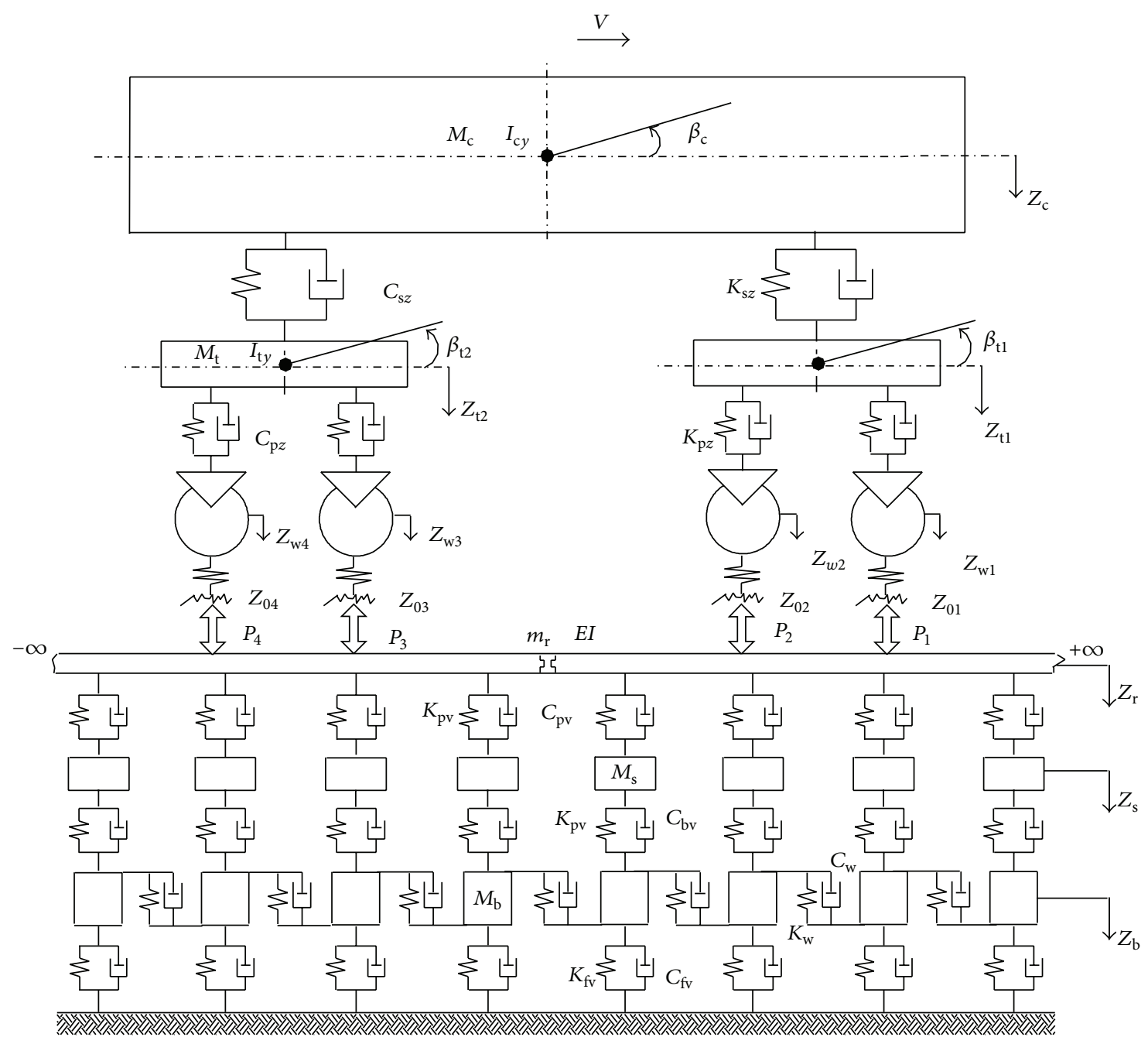

FIGURE 6: Three-dimensional vehicle-track coupled dynamic model (elevation).

noticeable that $P_{1}$ force is mainly dominated by the highfrequency interactions, while $P_{2}$ force is done by the mediumfrequency interactions.

Figure 9 displays the simulated response of the rail support force delivered to the rail bottom through the rail fastening and the rail pad. Under the excitation of the rail spalling, the maximum value of the rail support force is $38.82 \mathrm{kN}$.

The vertical acceleration response of the rail by simulation is represented in Figure 10. It indicates that the maximum value of the rail acceleration is about $68.2 \mathrm{~g}$.

\subsection{Effect of Running Speed on Wheel-Rail Vertical Force.} The maximum values of the wheel-rail force with the speed ranging from $250 \mathrm{~km} / \mathrm{h}$ to $350 \mathrm{~km} / \mathrm{h}$ are shown in Figure 11 . It can be observed that there is little influence of the running speed on the maximum wheel-rail vertical force. For example, the maximum value of the wheel-rail vertical force is $137.35 \mathrm{kN}$ at the speed of $250 \mathrm{~km} / \mathrm{h}$, while it is $136.05 \mathrm{kN}$ at the speed of $350 \mathrm{~km} / \mathrm{h}$.
What is noteworthy is that the running speed is in the scope of $250-350 \mathrm{~km} / \mathrm{h}$, which is much larger than the critical impact speed, $V_{\text {cro }}$, and it seems to be infinite. Under this situation, the impact velocity obtained by (6) can be rewritten as

$$
\bar{v}_{0}=\lim _{V \rightarrow \infty} v_{0}=\gamma L \sqrt{\frac{\mu}{R}} .
$$

As a consequence, the impact velocity will decrease slightly and is finally kept as a constant with the growth of the running speed. It is the main reason why the running speed has little effect on the wheel-rail vertical force.

4.3. Effect of Wheel Radius on Wheel-Rail Vertical Force. For the sake of investigating the effect of the wheel radius on the wheel-rail dynamic performance in this section, a set of wheel radiuses are assumed as $400 \mathrm{~mm}, 430 \mathrm{~mm}, 450 \mathrm{~mm}$, and $480 \mathrm{~mm}$. Thus, the corresponding critical lengths of the rail spalling are $56.53 \mathrm{~mm}, 58.62 \mathrm{~mm}, 59.97 \mathrm{~mm}$, and $61.94 \mathrm{~mm}$, respectively. 


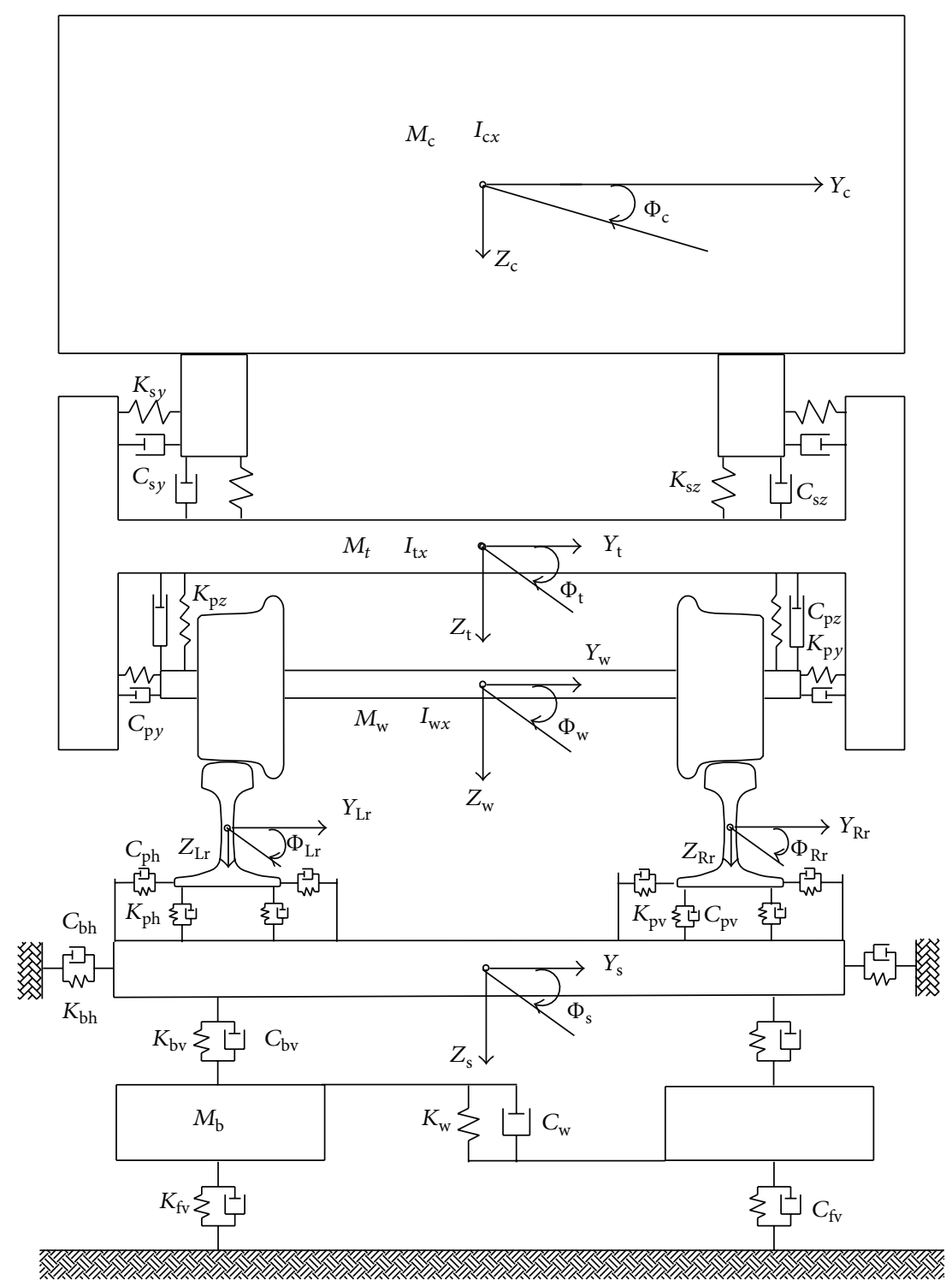

FIGURE 7: Three-dimensional vehicle-track coupled dynamic model (end view).

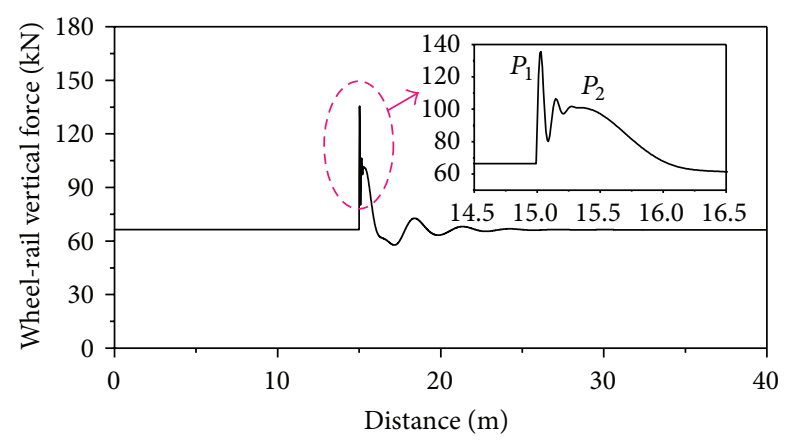

FIGURE 8: Wheel-rail vertical forces in time domain.

Due to the excitation of the spalling with a length of $30 \mathrm{~mm}$ and a depth of $1 \mathrm{~mm}$, the effect of the wheel radius on the maximum value of the wheel-rail vertical force at a speed

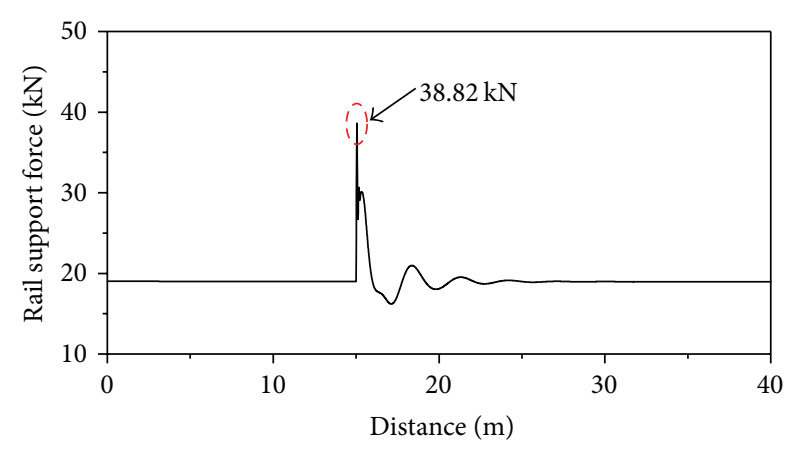

FIGURE 9: Rail support force in time domain.

of $350 \mathrm{~km} / \mathrm{h}$ is plotted in Figure 12. With the growth of the wheel radius, the wheel-rail vertical force decreases linearly. But the amplitude of reduction is very small. For instance, 


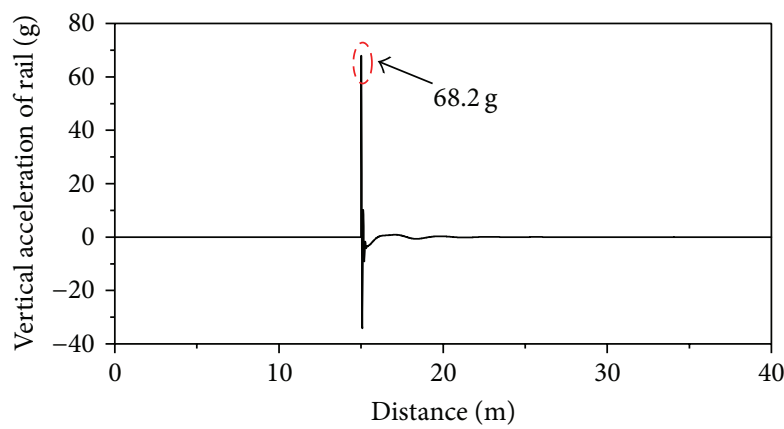

FIgURE 10: Vertical acceleration of rail in time domain.

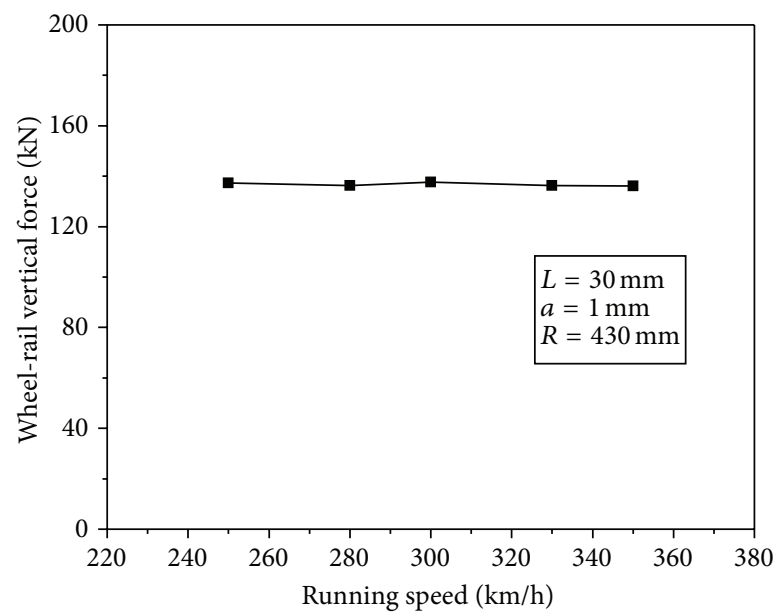

FIGURE 11: Wheel-rail vertical force versus running speeds.

the maximum wheel-rail vertical force will reduce by about $0.8 \mathrm{kN}$ for every increment of $10 \mathrm{~mm}$ in the wheel radius.

4.4. Effect of Impact Acceleration on Wheel-Rail Vertical Force. According to (3), the impact acceleration of the wheel set is only related to the sprung and the unsprung mass of the primary suspension in the vehicle. In this section, the ratio of the sprung mass to the unsprung mass is defined as

$$
\eta=\frac{M_{1}}{M_{2}} .
$$

Thus, the impact acceleration of the wheel set can be rewritten as

$$
\mu=(\eta+1) g .
$$

Under the situation that the ratio of $\eta$ is in the range of 4.097-9.194, the effects of the ratios on the maximum values of the wheel-rail vertical forces and the impact acceleration at a speed of $350 \mathrm{~km} / \mathrm{h}$ are shown in Figure 13. The impact acceleration of the wheel set will increase with the growth of the ratio, which causes the wheel-rail vertical force to increase. For example, the wheel-rail vertical force increases by about $5 \mathrm{kN}$ for every $10 \mathrm{~m} / \mathrm{s}^{2}$ increment in the impact acceleration.

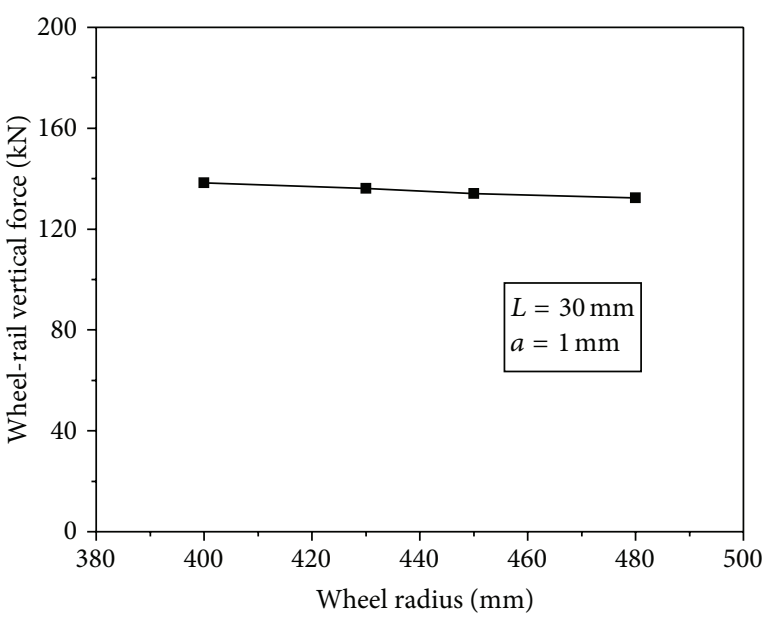

FIgURE 12: Wheel-rail vertical force versus wheel radius.

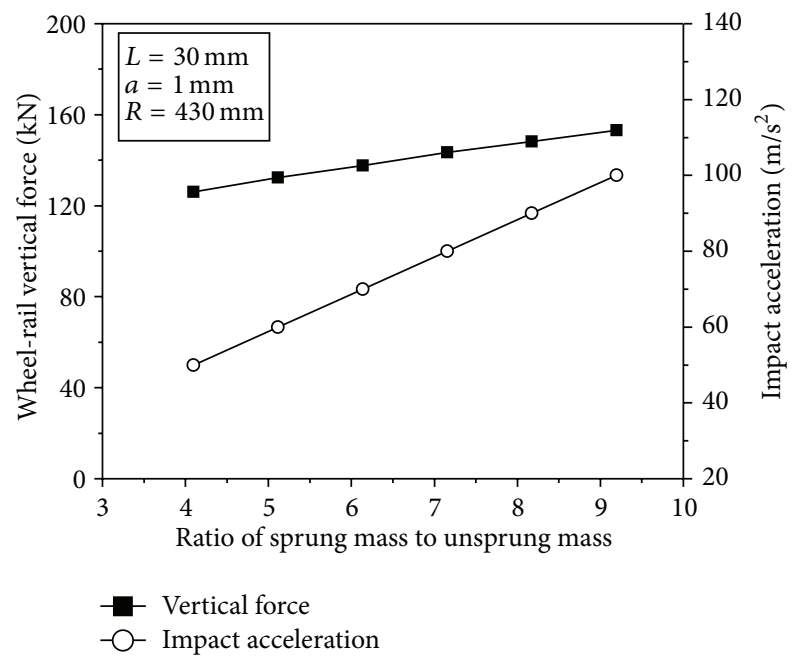

FIGURE 13: Wheel-rail vertical force and impact acceleration versus ratio of sprung mass to unsprung mass.

\section{Wheel-Rail Dynamic Interaction due to Harmonic Excitation}

In order to expose the wheel-rail dynamic interaction under the harmonic excitation, the rail spalling depth and length are assumed to be $1 \mathrm{~mm}$ and $100 \mathrm{~mm}$, respectively. The type and radius of the wheel are kept the same as those for the pulse excitation case; thus, the critical length is also $58.62 \mathrm{~mm}$.

5.1. Characteristics of Wheel-Rail Vibration. When the highspeed vehicle passes through this spalling region at a speed of $350 \mathrm{~km} / \mathrm{h}$, the calculated results of wheel-rail vertical force is shown in Figure 14. It illustrates that a violent dynamic interaction between the wheel and the rail is generated due to this harmonic spalling excitation, and the maximum value of wheel-rail vertical force is more than $500 \mathrm{kN}$. In addition, the phenomenon of the wheel jumping off the rail appears instantaneously, which is the same as the results due to the excitation of rail corrugation [22]. 


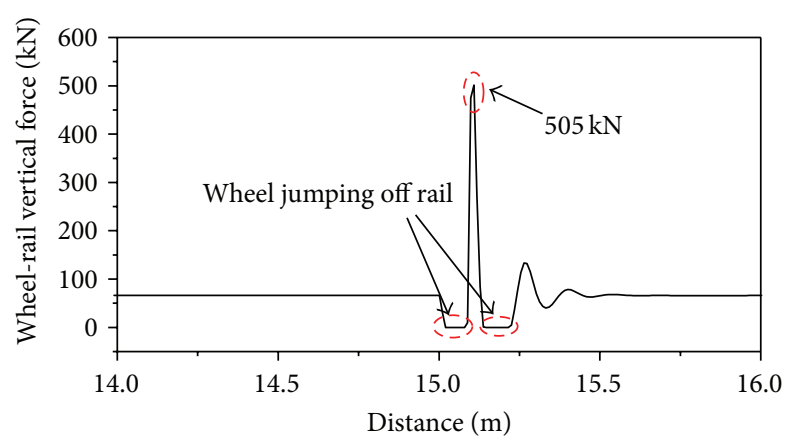

FIGURE 14: Wheel-rail vertical force in time domain.

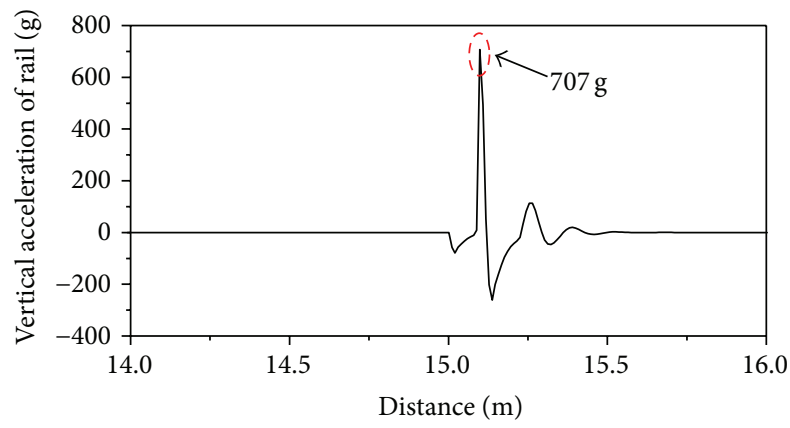

FIGURE 15: Vertical acceleration of rail in time domain.

Once the wheel loses contact with the rail instantaneously and then falls down and contacts with the rail again, an enormous impact force between the wheel and the rail will be produced, which can cause severe vibration to the rail. Figure 15 depicts the acceleration responses of the rail under this condition by simulation. It can be seen that the maximum value of the rail acceleration is about $700 \mathrm{~g}$.

5.2. Effect of Running Speed on Wheel-Rail Vertical Force. Under the condition that the speed is ranging from $250 \mathrm{~km} / \mathrm{h}$ to $350 \mathrm{~km} / \mathrm{h}$, the maximum values of wheel-rail vertical forces by simulation are shown in Figure 16. It can be found that the wheel-rail vertical force decreases with the increase of the speed, and the wheel-rail vertical forces are larger than $500 \mathrm{kN}$. For example, the maximum value of the wheelrail force is $644.1 \mathrm{kN}$ at the speed of $250 \mathrm{~km} / \mathrm{h}$, while it becomes $505 \mathrm{kN}$ at the speed of $350 \mathrm{~km} / \mathrm{h}$. Its reason lies in the relationship between the main frequencies of the wheel-rail vertical force and the excitation frequency. If the excitation frequency comes near to the main frequency, the value of the wheel-rail vertical force will become much greater [22]. The main frequency for the wheel-rail system employed in this paper is in the vicinity of $700 \mathrm{~Hz}$. To be more exact, when the speed is $250 \mathrm{~km} / \mathrm{h}$ and the spalling length is $100 \mathrm{~mm}$, the excitation frequency is $694.4 \mathrm{~Hz}$, while it is $972.2 \mathrm{~Hz}$ at the speed of $350 \mathrm{~km} / \mathrm{h}$. As a result, the excitation frequency at the speed of $250 \mathrm{~km} / \mathrm{h}$ is closer to the main frequency than that at the speed of $350 \mathrm{~km} / \mathrm{h}$.

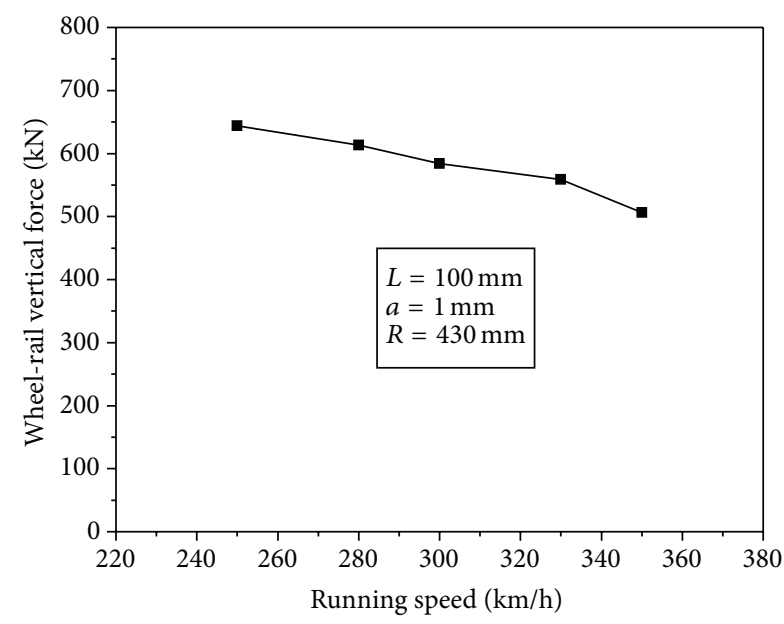

FIGURE 16: Wheel-rail vertical force versus running speeds.

\section{The Safety Threshold of Rail Spalling Length}

6.1. The Control Principle for Rail Spalling. The results mentioned above show that the wheel-rail dynamic interaction under the harmonic excitation is more serious than that under the pulse excitation for the rail spalling with the same depth. For example, the maximum value of the wheel-rail vertical force excited by the harmonic excitation is four times larger than that by the pulse excitation, and it is ten times that for the rail acceleration. That is to say, if the excitation mode is in the form of the harmonic irregularity, a violent wheel-rail dynamic interaction would be generated, while it would become less mild for the excitation with the shape of a pulse. However, the excitation mode in wheel-rail system is determined by the matching relationship between the spalling length and its critical length.

It is a key point to control the rail spalling length which should be less than its critical length for any spalling depth. Thus, the excitation mode in wheel-rail system caused by the rail spalling is in the shape of the pulse instead of the harmonic mode. So, according to this principle, the maximum of the rail spalling length is investigated in this section.

It is worth pointing out that effects of the running speed and the wheel radius on the wheel-rail dynamic interaction can be neglected under the situation that the spalling length is less than its critical length (shown in Figures 11 and 12). Consequently, a running speed of $350 \mathrm{~km} / \mathrm{h}$ and the wheel radius of $430 \mathrm{~mm}$ are employed for the case study in this section. In addition, the wheel-rail vertical force is taken as the most important safety index, whose limited value is $170 \mathrm{kN}$ by the relevant evaluation specification [23].

\subsection{Effect of Rail Spalling Length on Wheel-Rail Vertical Force.} The spalling depth is usually more than $1 \mathrm{~mm}$ on the rail surface, which is mainly focused on here. So, the corresponding critical length is more than $58 \mathrm{~mm}$ for this type of the rail spalling. According to the control principle mentioned above, the rail spalling length should be less than $58 \mathrm{~mm}$. 
TABLE 1: Threshold value of the spalling length with different impact acceleration.

\begin{tabular}{|c|c|c|c|c|c|c|}
\hline Impact acceleration $\left(\mathrm{m} / \mathrm{s}^{2}\right)$ & 50 & 60 & 70 & 80 & 90 & 100 \\
\hline Threshold value of the spalling length (mm) & 50.36 & 45.85 & 42.20 & 39.25 & 37.09 & 35.11 \\
\hline
\end{tabular}

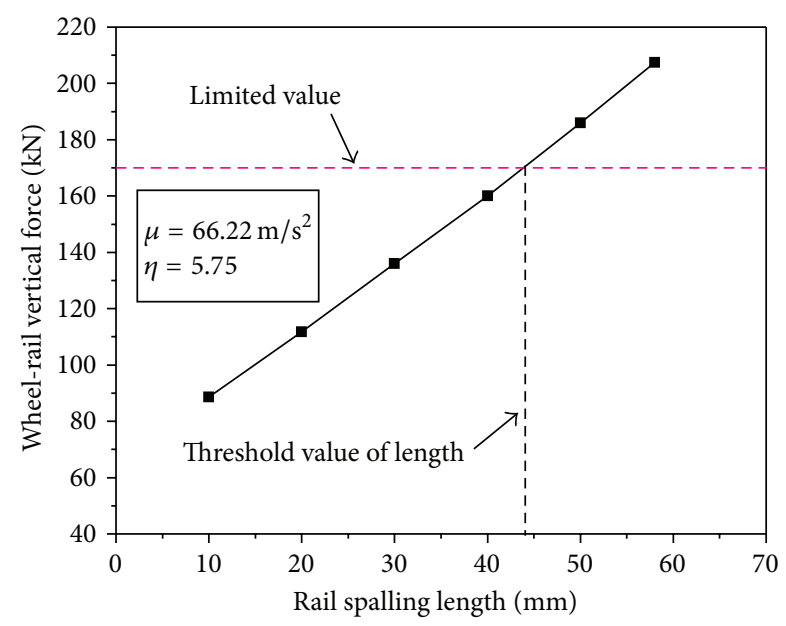

FIGURE 17: Influence of spalling length on the wheel-rail vertical force.

Thus, a series of spalling lengths are assumed within the range from $10 \mathrm{~mm}$ to $60 \mathrm{~mm}$ with an interval of $10 \mathrm{~mm}$. The critical length of $58 \mathrm{~mm}$ is also included.

Figure 17 depicts influence of the spalling length on the maximum value of the wheel-rail vertical force by simulation, where the impact acceleration of the wheel set is $66.22 \mathrm{~m} / \mathrm{s}^{2}$ and the ratio of the sprung mass to the unsprung mass is 5.75. It can be seen that the wheel-rail vertical force increases almost linearly with the growth of the rail spalling length. The maximum value of the wheel-rail vertical force is up to the limited value, namely, $170 \mathrm{kN}$, when the rail spalling length increases to $43.8 \mathrm{~mm}$. It means that the threshold value of the rail spalling length is $43.8 \mathrm{~mm}$ under these conditions.

6.3. Effect of Wheel Set Impact Acceleration on Threshold Value of Spalling Length. The sprung and the unsprung mass are different for different types of high-speed vehicles, resulting in the various wheel set impact acceleration of the rail spalling. It also can be known from Figure 13 that the larger the wheel set impact acceleration is, the greater the wheelrail dynamic interaction will be. Therefore, the wheel set impact acceleration might have significant influence on the safety threshold of the rail spalling length. In this subsection, the threshold values of the rail spalling length are calculated under the conditions of different impact acceleration.

For the investigation, the impact acceleration of the wheel set is designated within the scope of $50-100 \mathrm{~m} / \mathrm{s}^{2}$, where the limit conditions are taken into account. Accordingly, the ratio of the sprung mass to the unsprung mass varies from 4.1 to 9.19. The threshold values of the spalling length with different impact acceleration are given in Table 1. It can be seen that the larger the impact acceleration is, the smaller the threshold value of the spalling length will be. For example, the threshold value of the spalling length is $45.85 \mathrm{~mm}$ when the impact acceleration is $60 \mathrm{~m} / \mathrm{s}^{2}$, while it is only $35.11 \mathrm{~mm}$ when the impact acceleration is $100 \mathrm{~m} / \mathrm{s}^{2}$.

The analysis mentioned above indicates that, for the highspeed railway with the speed of $350 \mathrm{~km} / \mathrm{h}$, the maximum value of the rail spalling length is $35.11 \mathrm{~mm}$ under the condition that the spalling depth is $1 \mathrm{~mm}$ or more. By considering the convenience of practical application, it is recommended that the maximum value of the rail spalling length should be $35 \mathrm{~mm}$.

\section{Conclusions}

Based on the theory of vehicle-track coupled dynamics, wheel-rail dynamic vibration excited by the rail spalling in high-speed railway is analyzed. The following conclusions can be obtained:

(1) Two kinds of excitation modes in wheel-rail system, including the pulse excitation and the harmonic excitation, are generated due to the rail spalling. The excitation mode can be judged by the ratio of the spalling length to its critical length. If the ratio is lower than one, it is the pulse excitation; otherwise, it is the harmonic excitation.

(2) When a high-speed vehicle passes through the area with a rail spalling forming the pulse excitation, an enormous wheel-rail impact force is generated with a first peak and a second peak. The analyzed results indicate that the running speed and the wheel radius have little effect on the wheel-rail force, while the wheel set impact acceleration has an obvious effect on the wheel-rail force. On the other hand, a violent impact between the wheel and the rail will be produced for the harmonic excitation mode, and the phenomenon that the wheel jumps off the rail instantaneously appears repeatedly. In addition, the running speed has an obvious effect on the wheel-rail force.

(3) It is very important to control the spalling length firstly for investigating the safety threshold of the rail spalling. The control principle is that the spalling length should be less than its critical length for any spalling depth, so as to make the wheel-rail system under the pulse excitation instead of the harmonic excitation.

(4) Under the situation of the pulse excitation with the depth being $1 \mathrm{~mm}$ or more, the wheel-rail vertical force increases linearly with the growth of the spalling length. If the length of the rail spalling is no larger 
than $35 \mathrm{~mm}$, the vehicle at the speed of $350 \mathrm{~km} / \mathrm{h}$ will be in a safe condition.

In practice, there are usually multiple spallings existing on the rail surface. Investigations on the dynamic excitations from multiple spallings will be studied in our future work even if they are beyond the scope of this paper.

\section{Nomenclature for the Parameters}

\begin{tabular}{|c|c|}
\hline$M_{\mathrm{c}}:$ & Mass of a car body \\
\hline$M_{\mathrm{t}}:$ & Mass of a bogie \\
\hline$M_{\mathrm{w}}:$ & Mass of a wheel set \\
\hline$M_{\mathrm{r}}:$ & Mass of a rail per meter \\
\hline$M_{s}:$ & Mass of a sleeper \\
\hline$M_{\mathrm{b}}:$ & Mass of a ballast \\
\hline$I_{\mathrm{cy}}, I_{\mathrm{cx}}:$ & $\begin{array}{l}\text { Pitch and roll moment of inertia of a car body, } \\
\text { respectively }\end{array}$ \\
\hline$I_{\mathrm{ty}}, I_{\mathrm{tx}}:$ & $\begin{array}{l}\text { Pitch and roll moment of inertia of a bogie, } \\
\text { respectively }\end{array}$ \\
\hline & Roll moment of inertia of a wheel set \\
\hline EI: & Bending stiffness of a rail \\
\hline$K_{\mathrm{sz}}, K_{\mathrm{sy}}:$ & $\begin{array}{l}\text { Vertical and lateral stiffness of the secondary } \\
\text { suspension, respectively }\end{array}$ \\
\hline$C_{s z}, C_{s y}:$ & $\begin{array}{l}\text { Vertical and lateral damping of the secondary } \\
\text { suspension, respectively }\end{array}$ \\
\hline$K_{\mathrm{pz}}, K_{\mathrm{py}}:$ & $\begin{array}{l}\text { Vertical and lateral stiffness of the primary } \\
\text { suspension, respectively }\end{array}$ \\
\hline$C_{\mathrm{pz}}, C_{\mathrm{py}}$ & $\begin{array}{l}\text { Vertical and lateral damping of the primary } \\
\text { suspension, respectively }\end{array}$ \\
\hline$K_{\mathrm{pv}}, K_{\mathrm{ph}}:$ & $\begin{array}{l}\text { Vertical and lateral stiffness between rail and } \\
\text { sleeper, respectively }\end{array}$ \\
\hline$C_{\mathrm{pv}}, C_{\mathrm{ph}}$ & $\begin{array}{l}\text { Vertical and lateral damping between rail and } \\
\text { sleeper, respectively }\end{array}$ \\
\hline$K_{\mathrm{bv}}:$ & Vertical stiffness between sleeper and ballast \\
\hline$C_{\mathrm{bv}}:$ & Vertical damping between sleeper and ballast \\
\hline$K_{\mathrm{fv}}:$ & Vertical stiffness between ballast and subgrade \\
\hline$C_{\mathrm{fv}}:$ & Vertical damping between ballast and subgrade \\
\hline$K_{\mathrm{w}}:$ & Shear stiffness between front and back ballast \\
\hline$C_{\mathrm{w}}:$ & Shear damping between front and back ballast \\
\hline$\beta_{c}, \Phi_{c}:$ & Pitch and roll motion of a car body, respectively \\
\hline$\beta_{\mathrm{ti}}, \Phi_{\mathrm{ti}}:$ & $\begin{array}{l}\text { Pitch and roll motion of a bogie }(i=1,2) \text {, } \\
\text { respectively }\end{array}$ \\
\hline$\beta_{\mathrm{wi}}, \Phi_{\mathrm{wi}}:$ & $\begin{array}{l}\text { Pitch and roll motion of a wheel set }(i=1 \sim 4) \text {, } \\
\text { respectively }\end{array}$ \\
\hline$Z_{c}, Y_{c}:$ & $\begin{array}{l}\text { Vertical and lateral motion of a car body, } \\
\text { respectively }\end{array}$ \\
\hline$Z_{\mathrm{ti}}, Y_{\mathrm{ti}}:$ & $\begin{array}{l}\text { Vertical and lateral motion of a bogie }(i=1,2) \text {, } \\
\text { respectively }\end{array}$ \\
\hline$Z_{\mathrm{wi}}, Y_{\mathrm{wi}}:$ & $\begin{array}{l}\text { Vertical and lateral motion of a wheel set } \\
(i=1 \sim 4) \text {, respectively }\end{array}$ \\
\hline$Z_{\mathrm{r}}:$ & Vertical motion of a rail \\
\hline$Y_{\mathrm{Lr}}, Y_{\mathrm{Rr}}:$ & Lateral motion of left and right rail, respectively \\
\hline$Z_{\mathrm{s}}, Y_{\mathrm{s}}:$ & $\begin{array}{l}\text { Vertical and lateral motion of a sleeper, } \\
\text { respectively }\end{array}$ \\
\hline$Z_{\mathrm{b}}:$ & Vertical motion of a ballast \\
\hline & Irregularity in wheel-rail system $(i=1 \sim 4)$ \\
\hline$P_{i}:$ & Wheel-rail vertical force $(i=1 \sim 4)$ \\
\hline
\end{tabular}

\section{Competing Interests}

The authors declare that they have no competing interests.

\section{Acknowledgments}

This work was supported by the National Basic Research Program of China (973 Program) under Grants no. 2013 CB036206 and no. 2013CB036205.

\section{References}

[1] D. F. Cannon and H. Pradier, "Rail rolling contact fatigue research by the European Rail Research Institute," Wear, vol. 191, no. 1-2, pp. 1-13, 1996.

[2] J. Sun, K. J. Sawly, D. H. Stone, and D. F. Teter, "Progress in the reducing of wheel spalling," in Proceedings of the 12th International Congress on Wheelset, pp. 18-29, Qingdao, China, September 1998.

[3] Y. Sato and A. Matsumoto, "Review on rail corrugation studies," in Proceeding of the 5th International Congress on Contact Mechanics and Wear of Wheel/Rail System, Japan, pp. 74-80, Tokyo, Japan, July 2000.

[4] Y. R. Jiang and H. Sehitoglu, "Fatigue and stress analysis of rolling contact," Tech. Rep. 161, UILU-ENG 923602, University of Illinois at Champaign, 1992.

[5] J. J. Kalker, Three-Dimensional Elastic Bodies on Rolling Contact, Kluwer Academic, Dordrecht, The Netherlands, 1990.

[6] K. L. Knothe, A. Theiler, and S. Güney, "Investigation of contact stress on the wheel/rail-system at steady state curving," Vehicle System Dynamics, vol. 33, pp. 616-628, 2000.

[7] J. C. Simo and T. A. Laursen, "An augmented lagrangian treatment of contact problems involving friction," Computers and Structures, vol. 42, no. 1, pp. 97-116, 1992.

[8] P. Wriggers and G. Zavarise, "Application of augmented Lagrangian techniques for non-linear constitutive laws in contact interfaces," Communications in Numerical Methods in Engineering, vol. 9, no. 10, pp. 815-824, 1993.

[9] P. Alart and A. Curnier, "A mixed formulation for frictional contact problems prone to Newton like solution methods," Computer Methods in Applied Mechanics and Engineering, vol. 92, no. 3, pp. 353-375, 1991.

[10] M. Olzak, J. Stupnicki, and R. Wojcik, "Investigation of crack propagation during contact by a finite element method," Wear, vol. 146, no. 2, pp. 229-240, 1991.

[11] M. Olzak, J. Stupnicki, and R. Wójcik, "Numerical analysis of 3D cracks propagating in the rail-wheel contact zone," in Rail Quality and Maintenance for Modern Railway Operation, J. J. Kalker, D. F. Cannon, and O. Orringer, Eds., pp. 385-395, 1993.

[12] S. Bogdański, M. Olzak, and J. Stupnicki, "Numerical stress analysis of rail rolling contact fatigue cracks," Wear, vol. 191, no. 1-2, pp. 14-24, 1996.

[13] R. Smallwood, J. C. Sinclair, and K. J. Sawley, "An optimization technique to minimize rail contact stresses," Wear, vol. 144, no. 1-2, pp. 373-384, 1991.

[14] K. Hou, J. Kalousek, H. Lamba et al., "Thermal effect on adhesion in wheel/rail," in Proceedings of the 5th International Congress on Contact Mechanics and Wear of Wheel/Rail System, pp. 239-244, Tokyo, Japan, July 2000. 
[15] K. Knothe and S. Liebelt, "Determination of temperatures for sliding contact with applications for wheel-rail systems," Wear, vol. 189, no. 1-2, pp. 91-99, 1995.

[16] M. Ishida and N. Abe, "Experimental study on rolling contact fatigue from the aspect of residual stress," Wear, vol. 191, no. 1-2, pp. 65-71, 1996.

[17] J. Eisenmann and G. Leykauf, "The effect of head checking on the bending fatigue strength of railway rails," in Proceedings of the International Conference on Rail Quality and Maintenance for Modern Railway Operation, pp. 373-384, Delft, The Netherlands, June 1992.

[18] J. Piotrowski, "Contact loading of a high rail in curves physical simulation method to investigate shelling," Vehicle System Dynamics, vol. 17, no. 1-2, pp. 57-79, 1988.

[19] H. Yokoyama, S. Mitao, S. Yamamoto et al., "Effect of the angle of attack on flaking behavior in pearlitic and bainitics steel," in Proceedings of the 5th International Congress on Contact Mechanics and Wear of Wheel/Rail System, pp. 154-160, Tokyo, Japan, July 2000.

[20] W. Zhai, K. Wang, and C. Cai, "Fundamentals of vehicle-track coupled dynamics," Vehicle System Dynamics, vol. 47, no. 11, pp. 1349-1376, 2009.

[21] W. Zhai and X. Sun, "A detailed model for investigating vertical interaction between railway vehicle and track," Vehicle System Dynamics, vol. 23, supplementl, pp. 603-615, 1994.

[22] K. Y. Wang, P. F. Liu, W. M. Zhai, C. Huang, Z. G. Chen, and J. M. Gao, "Wheel/rail dynamic interaction due to excitation of rail corrugation in high-speed railway," Science China Technological Sciences, vol. 58, no. 2, pp. 226-235, 2014.

[23] UIC CODE-518, “Testing and approval of railway vehicles from the point of view of their dynamic behaviour-safety-track fatigue-running behaviour," 2009. 


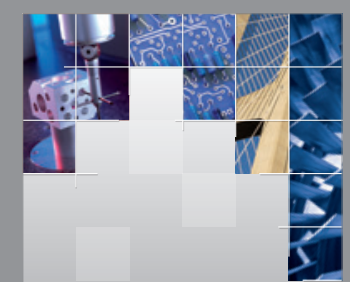

\section{Enfincering}
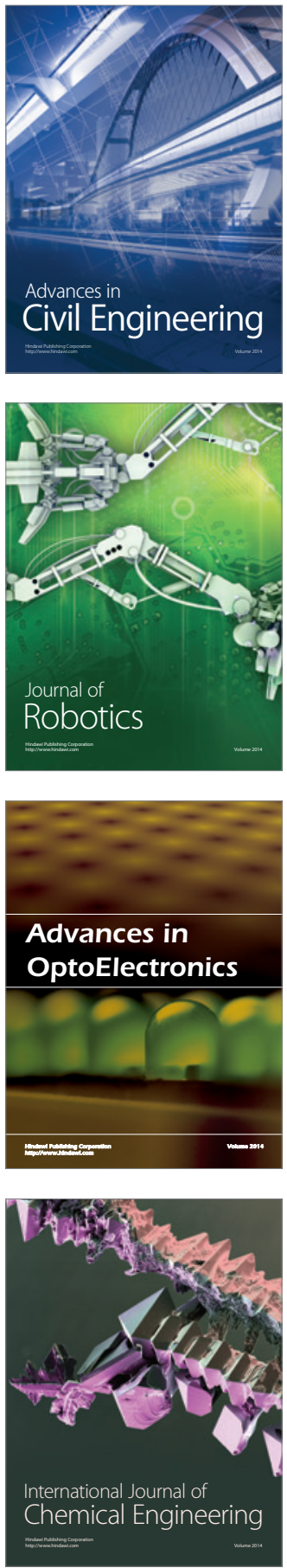

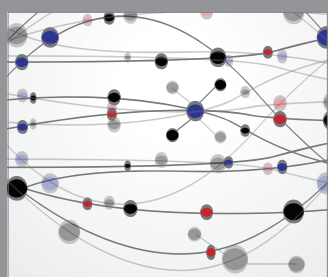

The Scientific World Journal

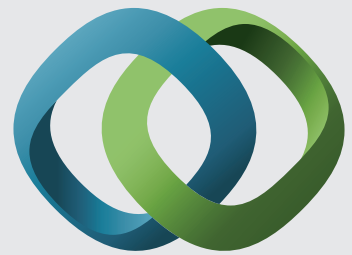

\section{Hindawi}

Submit your manuscripts at

http://www.hindawi.com
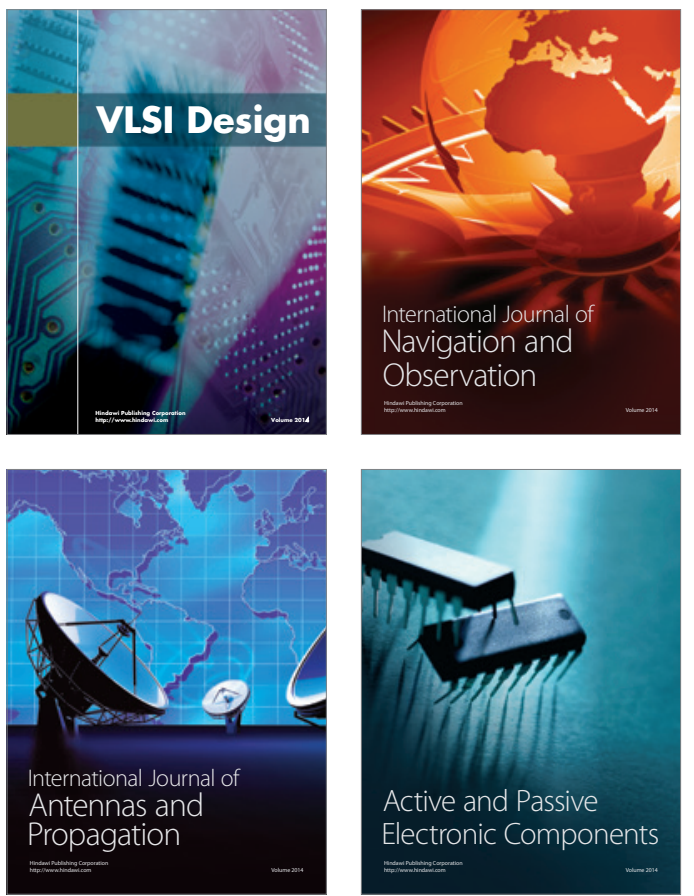
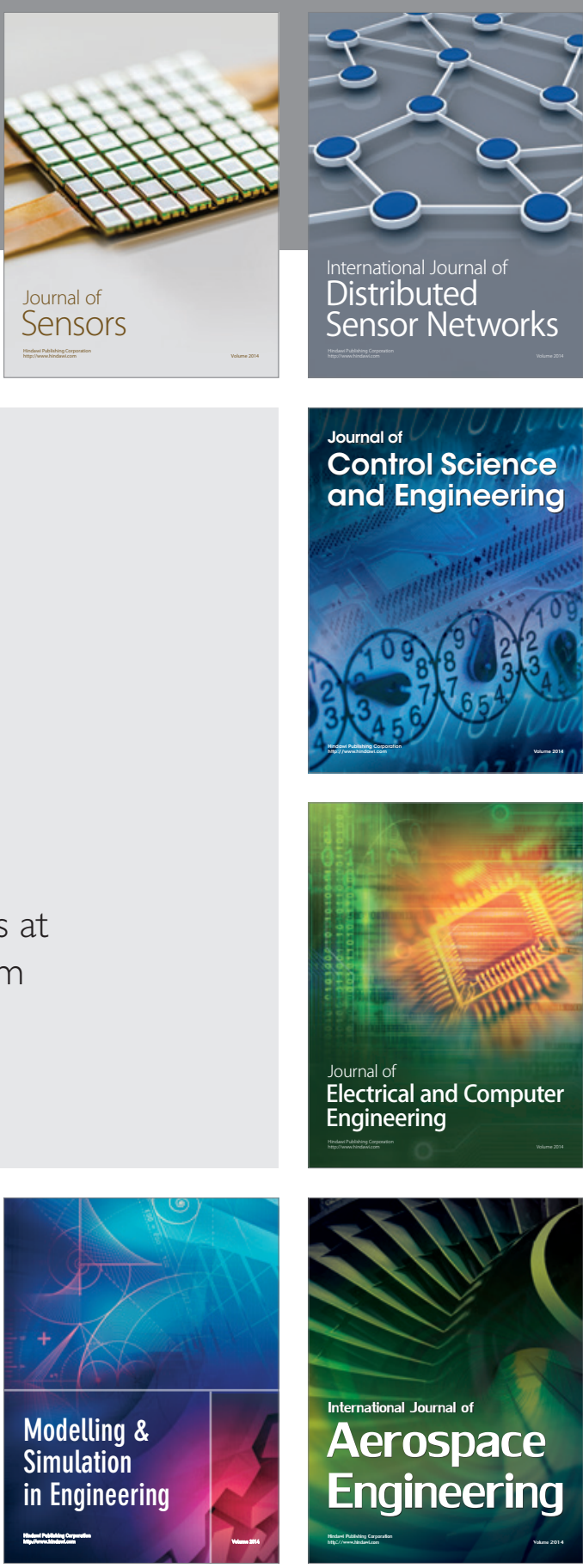

International Journal of

Distributed

Sensor Networks

Journal of

Control Science

and Engineering
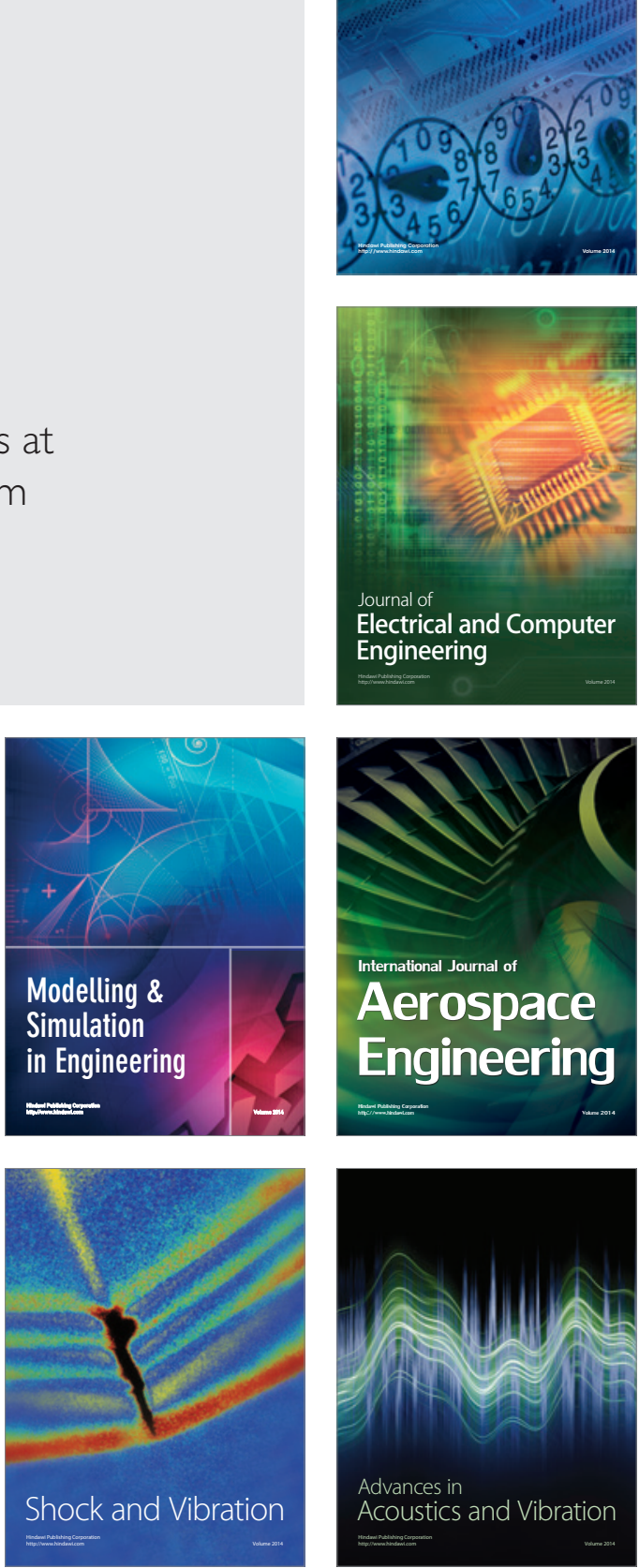